\title{
Mechanical and thermal behavior of polyvinyl alcohol reinforced with aligned carbon nanotubes
}

\author{
Sergio Alonso Medina Escobar ${ }^{1}$, César Augusto Isaza Merino ${ }^{1}$ \\ Juan Manuel Meza Meza ${ }^{1}$
}

\author{
${ }^{1}$ Tribology and Surfaces Group, Universidad Nacional de Colombia - Medellín \\ Escuela de materiales y minerales, Calle 75 No 79 A -5, Bloque M17 Medellín, Antioquia, Colombia, 050034. \\ e-mail: samedinae@unal.edu.co, cesarisaz@gmail.com,jmmezam@unal.edu.co
}

\begin{abstract}
In recent years, due to their high specific mechanical properties, the polymer matrix composites have been widely used. In particular, carbon nanotubes (CNTs) have been used as reinforcement due to its exceptional mechanical and electrical properties. In this work the mechanical behavior of polyvinyl alcohol (PVA) reinforced with different percentages of mechanically oriented CNTs was studied. The composite material was made starting with a solution of PVA+ distilled water, and then the CNTs were added to the solution and dispersed by magnetic stirring and ultrasonic agitation. During this step, a surfactant was added to help with the CNTs dispersion. This mixture was poured into a container and dried using a heat source to accelerate its polymerization and curing. The layers obtained were subjected to mechanical stretching at controlled temperature to align the CNTs in the loading direction. The mechanical properties were measured by tensile testing and nanoindentation. The results show a large increase in modulus and hardness compared with nonreinforced polymeric material, it was also found a significant increase in the tensile strength. The composite with the best properties was subjected to thermal stabilization by ethanol, obtaining an increase in the degradation temperature of about $100^{\circ} \mathrm{C}$ approximately, although in this case the mechanical stiffness and hardness were decreased compared to unstabilized material, the usefulness of this material is enhanced.
\end{abstract}

Keywords: Mechanical properties, Polymer matrix composites, Carbon nanotubes, Polyvinyl alcohol.

\section{INTRODUCTION}

Nowadays, the understanding and manipulation of the properties of composite materials at nanometer scale is the key for the development of this kind of materials. Because of its high specific properties, these materials can find applications in aerospace, aeronautics and automotive industries [1- $\underline{5}]$. During the last decade, the CNTs [6] have been extensively used as reinforcement in metallic, ceramic and especially in polymeric materials (see Figure 1). In general this has been due to an increased availability and cost reductions in the polymer matrix composites (PMCs) due to its relative easy dispersion. In addition, the functionalization of CNTs has great advantages when incorporated into polymeric matrices.

PMCs reinforced with CNTs are produced by a wide range of techniques; the key to achieve good properties in these materials is a good dispersion and control of the alignment of the CNTs. For this reason, polymers which can be easily dissolved [7-16] are preferred. Those CNTs are usually dispersed by ultrasonic agitation and the alignment of the CNTs is obtained by the imposition of an electric field during the curing period [17-25] or by stretching the composite [26]. In the last, case low energy levels are required. Polyvinyl alcohol (PVA) is easily dissolved in water, so it is convenient for CNTs incorporation. Small amounts of CNTs are required in order to get high modifications of PMCs' properties, typically in the order of 1 $\mathrm{wt} \%[27,28]$. However, one of the main problems of PVA intended to be used in structural applications is its degradation in water and its low temperature of service. In order to stabilize the PVA, cross-linking must be promoted, usually by irradiation, alternating freezing and thawing, or by using chemical reagents. Recently, soaking PVA into ethanol [29] or methanol has been proved to remove the residual water in the polymer increasing the formation of crystallites [30] . 
For these reasons, the present work explores the modification of mechanical properties on PVA due to: addition of CNTs to PVA, the mechanical orientation of CNTs and because of chemical stabilization [29].

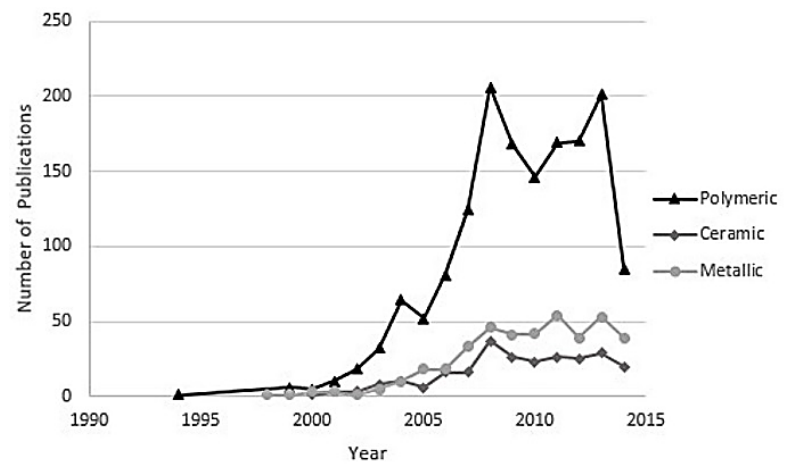

Figure 1: Number of publications in polymeric, ceramic and metallic matrices reinforced with CNTs [31].

\section{MATERIALS AND METHODS}

Pellets of fully hydrolyzed PVA were diluted in hot distilled water to produce a solution of 4 wt $\%$ of PVA. Multi-walled CNTs (MCNTs) were introduced into the PVA solution in percentages of $0.25,0.5$ and $1 \mathrm{wt} \%$ MCNTs were fabricated by CVD (Chemical Vapor Deposition) with inner diameters ranging between 10 and $30 \mathrm{~nm}$ and outer diameters between 25 and $50 \mathrm{~nm}$, a complete characterization can be found elsewhere [32].

The reinforcement of the composite was dispersed by magnetic stirring during one hour at an average speed of $600 \mathrm{rpm}$ followed by a sonication in a Vibra Cell series CLC equipment, it was set to a power of $100 \mathrm{~W}$ and an amplitude of the probe of $20 \%$; the dispersion maximum energy was $60 \mathrm{~kJ}$ in order to prevent the damage of the CNTs. Finally this mixture was cured at $38^{\circ} \mathrm{C}$ in a petry dish for 24 hours. From this composite, small sheets were cut into small sections of $150 \mathrm{~mm}$ x $20 \mathrm{~mm}$ x $200 \mathrm{microns}$; these samples were stretched using a Monsanto tensile machine at a speed of $2 \mathrm{~mm} / \mathrm{min}$ at a constant temperature of $75^{\circ} \mathrm{C}$. The final thicknesses were 100 microns for polymer reinforced at $0.25 \mathrm{wt} \%$ and 150 microns for polymers reinforced at $1 \mathrm{wt} \%$. The manufacture procedure is illustrated in Figure 2. In order to stabilize the composites, they were immersed in ethanol at $60^{\circ} \mathrm{C}$ for a period of 2 hours.

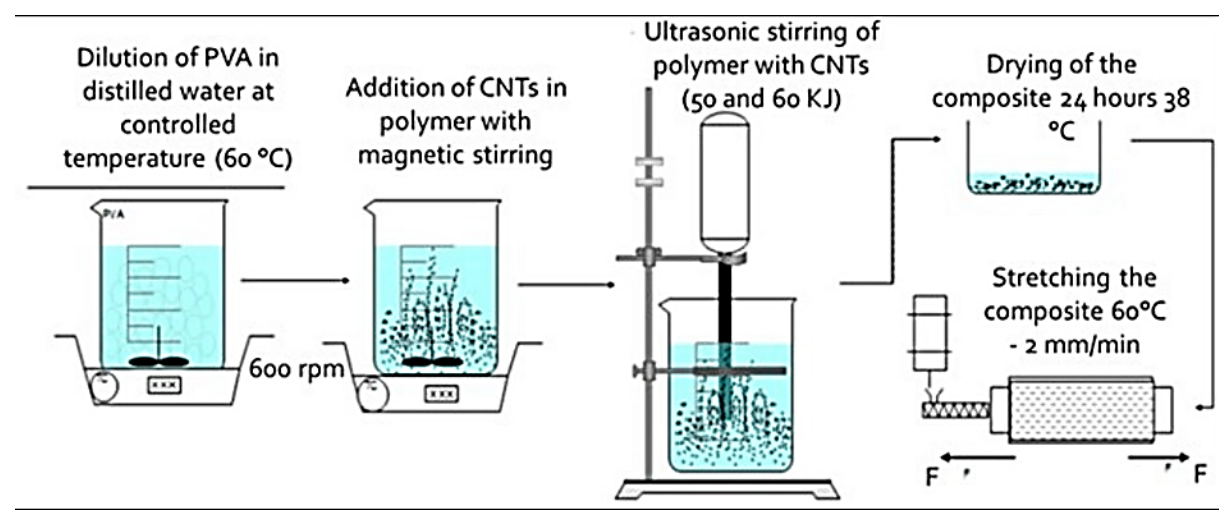

Figure 2: Procedure for polymer matrix composites reinforced with CNTs.

Tensile samples were tested in an AG Shimadzu model GX testing machine with a speed of $0.5 \mathrm{~mm} /$ min. Nanoindentation tests were performed in an IBIS Authority Fischer - Cripps nanoindenter equipped with a Berkovich indenter, following the Oliver and Pharr method. Thermogravimetric analysis (TGA) and differential scanning calorimetry (DSC) were performed in a Mettler Toledo AG - TGA/SDTA851 at a heating rate of $10^{\circ} \mathrm{C} \mathrm{min}^{-1}$ from $35^{\circ} \mathrm{C}$ up to $520^{\circ} \mathrm{C}$ in a nitrogen atmosphere which minimized the mass loss due to nanotube oxidation, whilst allowing the PVA to thermally decompose almost completely.

Stabilization process was done 10 months later the material fabrication. Thermal analysis was done for the composite that had the best mechanical properties $(0.5 \mathrm{wt} \% \mathrm{CNTs})$ measured 1 month after manufacture (see Figures $4 \mathrm{a}$ and 6). These samples were dried at room temperature during 2 days and after 
one week they were mechanically and thermally characterized again (see Figures 7 to 9). The notation used in reported results is: materials with reinforcement not aligned: NA (no stretching), and materials with reinforcement mechanically aligned: MA (stretched).

\section{RESULTS}

A study of the hardness and elastic modulus variation as function of indentation depth (or indentation load) is shown in Figure 3, i.e. it explores the change of these properties near the surface of the composite. This test was conducted a couple of weeks after the samples manufacture. Clearly it show that there is an increase in both properties near the surface, this is not due to an area function calibration or to an instrument's compliance because the equipment and indenter were properly calibrated. Instead of it, this is an Indentation Size Effect (ISE) probably due to a different polymerization degree near the surface because of with oxygen presence, or by the precipitation of CNTs at the composites' bottom surface during drying. It can also be seen that the properties are stabilized after about three microns in depth, so properties measured beyond this three micros are representative of the global effect of the CNTs addition into the materials' behavior, which is the work's goal. From now on, all nanoindentation experiments will be made at $100 \mathrm{mN}$, load which guarantees penetration depths well above 2 micrometers.

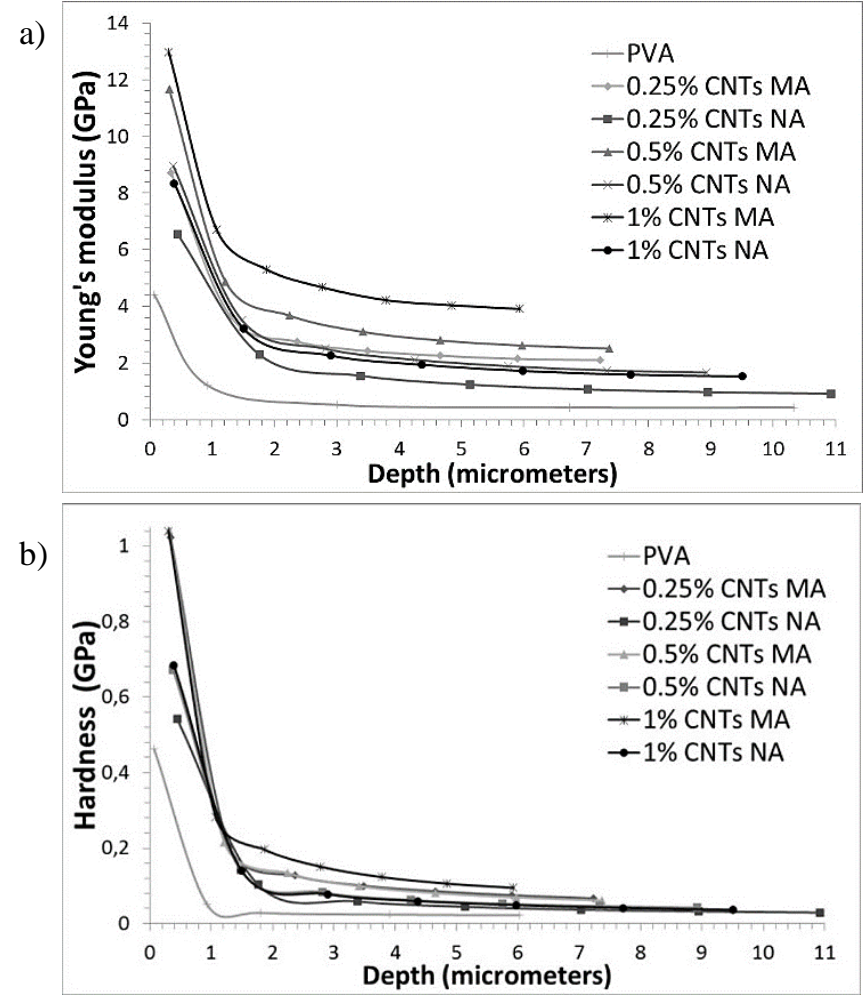

Figure 3: a) Young's modulus and b) hardness, measurement by nanoindentation under multiple unloading tests ( 2 weeks after manufacture).

Figure 4a shows a qualitative comparison of the elastic modulus measured by tensile test for all composites. In all cases an increase in this property is clearly seen, respect to unreinforced PVA samples. The measured elastic modulus is highly underestimated because during tensile test the deformation of the specimens was measured by the displacement between the clamps. These results are confirmed by nanoindentation test shown in Figure 4b. It is seen that the alignment of the polymeric chains in the PVA produces an increase in the properties; note that when the CNTs are aligned this increase is even bigger. It can be concluded that the composite achieves the maximum elastic modulus when $0.5 \mathrm{wt} \%$ of CNTs is added to the polymer. Higher percentages of CNTs can decrease the elastic modulus, the hardness and maximum strength as will be seen later. This is due to a bad CNTs dispersion, as supported by an increase in the standard deviation of the elastic modulus (Figure 4) and hardness (Figure 5) measured through nanoindentation, which in turns means that while nanoindentation is conducted the indenter is placed in 
zones with different microstructure; it means with different CNTs contents or different CNTs degrees of alignment. Note also that the unreinforced PVA produces results with small standard deviation and symmetrical confidence intervals, which is an indirect indication of the isotropy of the material, isotropy lost with the addition of CNTs and its subsequent alignment. Note that the addition of CNTs increases the mechanical properties (NA's samples) respect to PVA polymer; however the properties of the reinforced unstretched composites are almost constant no matter the CNTs content. Maximum tensile strength results are shown in Figure 6. Note that when the composite is stretched all mechanical properties suffer a dramatic increase (MA's samples), so Figures 4 to 6 allows concluding that the stretching plays a fundamental roll in the increasing of these properties.

It is worth to mention that maximum strength is already measured in the alignment direction while hardness and elastic modulus measured by nanoindentation are measured in the "bulk of the material", i.e. in all directions, so elastic modulus measured in the CNTs alignment direction (by tensile test) could probably produce bigger values than those reported here by nanoindentation.

Figure 6 also shows that the strength of the composite has a marked decrease for reinforcement additions higher than $0.5 \mathrm{wt} \%$. This certainly is due to CNTs agglomeration zones that act as stress concentrators affecting this property in a great extent compared with hardness and elastic modulus, reinforcing the hypothesis of a bad dispersion for CNTs contents above $0.5 \mathrm{wt} \%$.
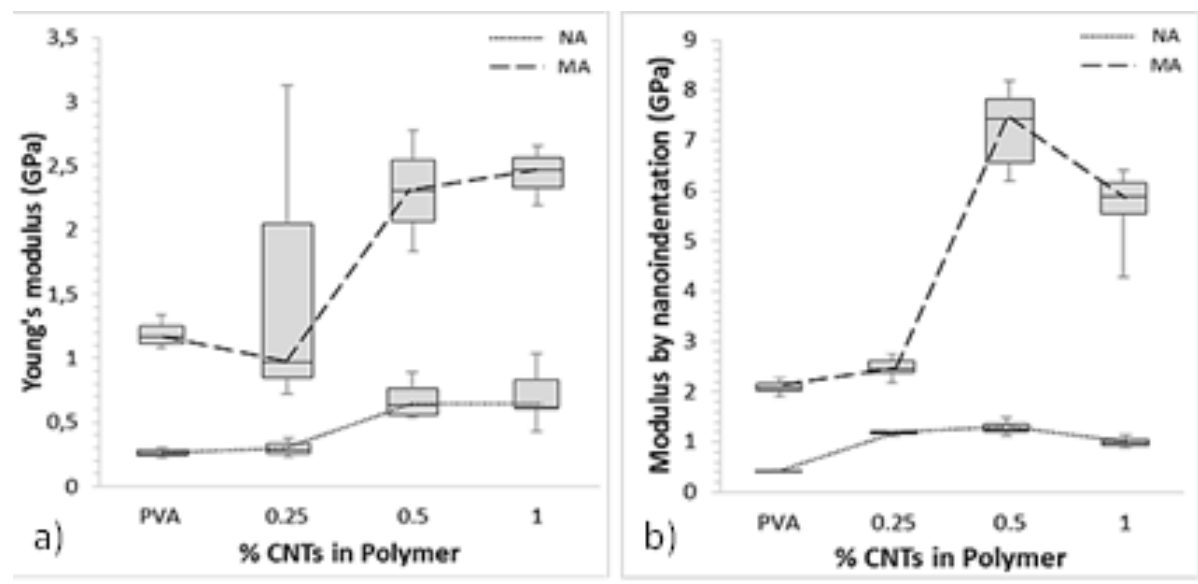

Figure 4: a) Young's modulus measurement by tension (2 weeks after manufacture), b) Young's modulus measurement by nanoindentation with a depth penetration of 5-11 microns ( 1 month after manufacture).

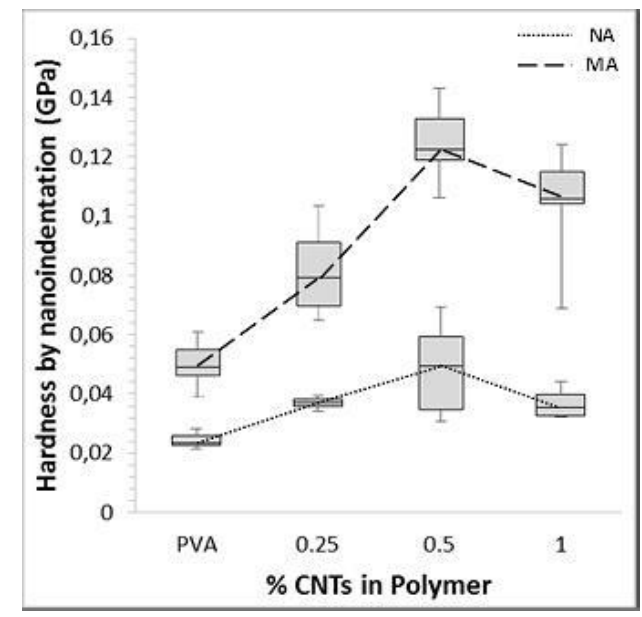

Figure 5: Hardness measured by nanoindentation test with a depth penetration of 5-11 microns (1 month after manufacture). 


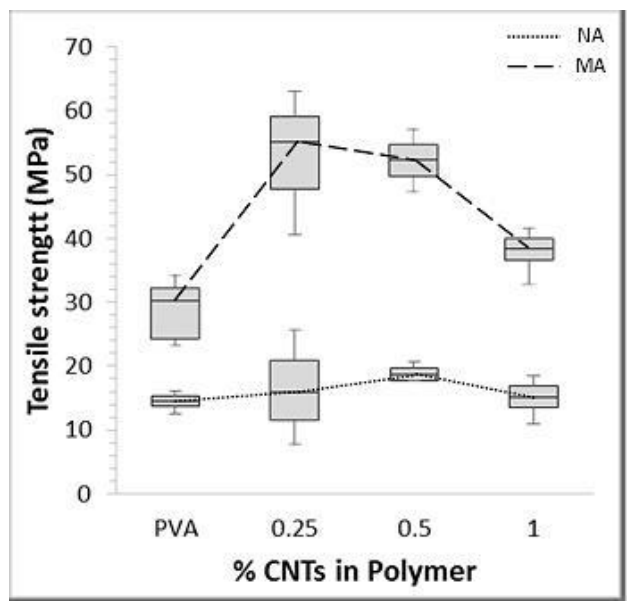

Figure 6: Maximum strength measured by tensile test ( 2 weeks after manufacture).

A comparison of previous results, Figures 4 to 6 , shows that the composite is stiffened as function of time elapsed since its manufacturing date. It can also be concluded that the composite with $0.5 \mathrm{wt} \%$ of CNTs is the one that presents the maximum mechanical properties. That is why it was decided to work on this composite to study the effect of stabilizing it (by soaking the material in ethanol) into its thermal behavior.

Figure 7 shows the TGA results of both materials: as produced (without stabilization) and submitted to the stabilization procedure. Initially all the curves show some weight gain because the material will absorb some humidity (Figure 7b) which is normal in water-soluble polymers as is PVA [34]. In all TGA curves there is a weight loss starting at about $100^{\circ} \mathrm{C}$ (labeled as $T_{100}$ in Figure 7), which follows to the glass transition temperature of the composites. Generally, at this stage, the materials that were stabilized shows a greater mass loss because of two reasons: unstabilized materials were stored during 10 months into a desiccators and they have lost water while stabilized ones eliminates waste water absorbed during the soaking, water which was not completely released during the drying and two storage days into the desiccators. As the equipment used in this research do not allows high vacuum in the heating chamber and just allows a single cycle, the accuracy of glass transition temperatures is not good enough; it must be noticed that same facts prevents that the crystallization kinetics can't be followed precisely.
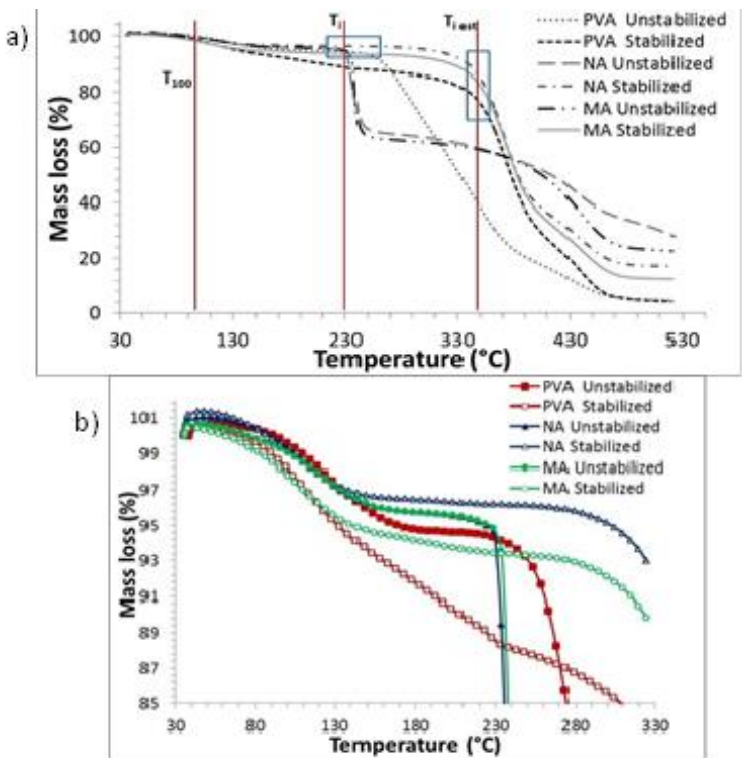

Figure 7: a) TGA curves of PVA and PVA with 5\% of CNTs (NA y MA).b) close up 
Then, the beginning of significant mass loss takes place, it occurs in the unstabilized materials at about $230^{\circ} \mathrm{C}$ (labeled as $T_{i}$ in Figure 7), while in the stabilized ones this occurs at about $350^{\circ} \mathrm{C}$ (labeled as $T_{\text {iest }}$ in Figure 7), as can be seen these temperatures does not depend on the CNTs alignment. It is at these temperatures where the polymer begins to break the chains, leading to the degradation of the PVA. A comparison of non-stabilized materials with reinforcement and without reinforcement (PVA) presents bigger $T_{i}$ for the last one showing that there is a slight negative effect of the CNTs into the starting of the unstabilized PVA decomposition. This is because the CNTs in the polymer contribute to a more severe degradation since they promote a lower crystallization temperature and lower fractional crystallinity as PROBST, et al [30] have reported. The behavior in the non-stabilized material is a result of absorption, by the activated carbon surface, of free-radicals generated during polymer decomposition. On the other hand, at higher temperatures the decomposition of the nanotube has a marked effect into the composite behavior [35] because the decomposition of the oxidized nanotubes surface consumes a lot of the energy of the process. However, the degradation starting temperature for stabilized materials $\left(T_{i e s t}\right)$ is substantially increased respect to non-stabilized ones. Mechanisms of this improvement will be explained below. This certainly allows for more commercial uses in engineering applications.

Figure 7 also shows that the PVA decomposes almost completely, leaving some residuals at $530^{\circ} \mathrm{C}$, it is required a higher temperature for total decomposition, anyway some residues will remain as ashes. In the case of composites, at this temperature CNTs are still present. Furthermore, it can be seen that the stabilized composites lose more weight than the unstabilized ones.

DSC tests are shown in Figure 8. It can be seen 3 different behaviors: the first one for unstabilized PVA, then the composites that were not stabilized and finally the PVA and composites which were stabilized, these last ones with a completely different behavior. As explained by KELEN [36] for unstabilized polymer, the nanotubes present an absorption of free radicals generated during the decomposition of the polymer, so the effect produced by the CNTs on PVA unstabilized is noticeable: A considerably increase in the rate of degradation is seen as indicated by the sharp peaks of the graph, which represent the melting transformation of PVA. On the other hand, the stabilized materials present a bigger crosslinking. This is reflected in Fig. 8 as a shift of the peaks to a bigger temperature and lower transformation rates. The results of the TGA and DSC analysis allows to conclude that the composites without stabilization promote the degradation of the PVA, showing a melting-transformation of the polymer at about $230-250^{\circ} \mathrm{C}$, while when the material is stabilized the melting transformation occurs at about $340^{\circ} \mathrm{C}$.

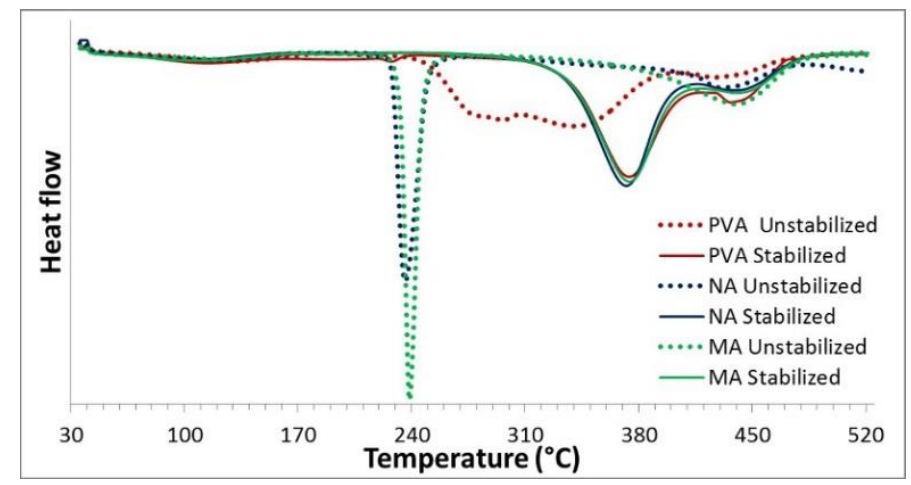

Figure 8: DSC curves of PVA and PVA with 5\% of CNTs (NA y MA).

Nanoindentation results for stabilized materials are shown in Figure 9. It is important to point out that the results were obtained 10 months after the manufacture process. Comparing Figure 9 with Figures $4 \mathrm{~b}$ and 5 , it can be clearly seen that the composite has been stiffened during this period of time, which is reflected as an increase in both the elastic modulus and hardness. Once the PVA is stabilized (soaked and dried), similar properties to those obtained after manufacture are obtained in the PVA without CNTs. However, in reinforced composites the stabilization produces a small reduction in the properties, showing that CTNs plays an important role in the stabilization process. Taking into account that the water in the polymers acts as a plasticizer, the stiffening phenomenon can be due to the water loss during the months elapsed because the 
samples were stored into a desiccators and again, the stabilization incorporates water into the composite which reduces the mechanical properties.

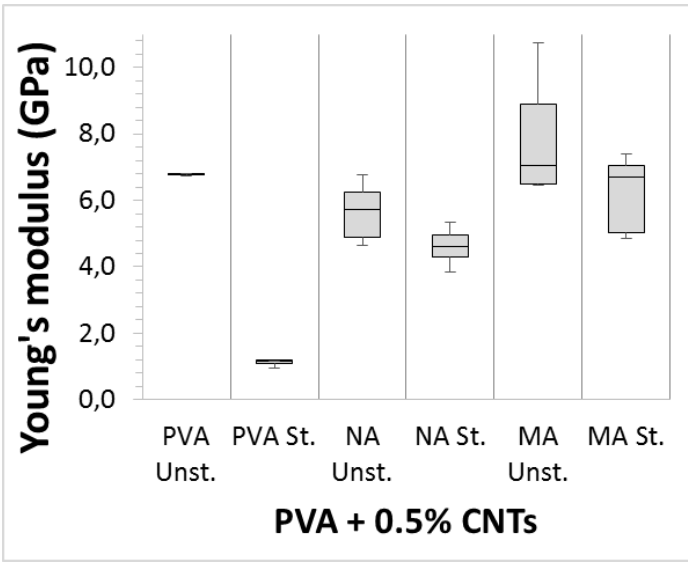

a)

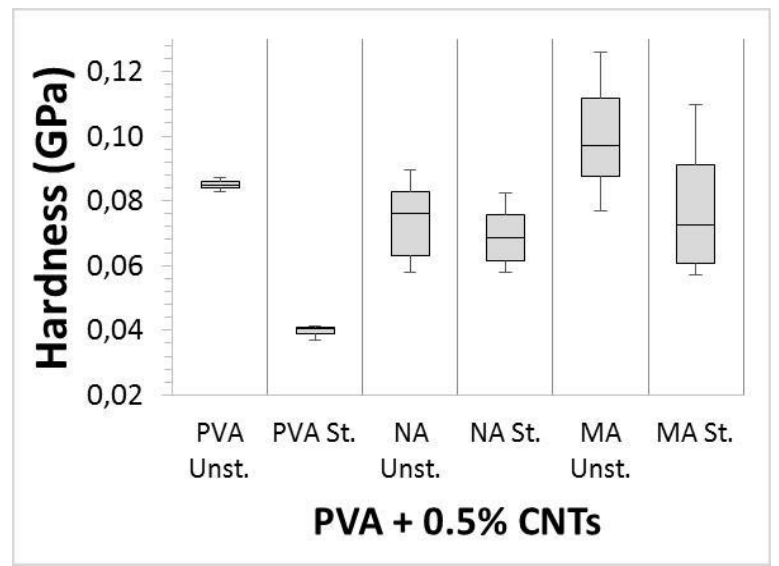

b)

Figure 9: Nanoindentation results measured on samples after 10 months of manufacture: a) Young's modulus and b) hardness, Comparison of stabilized (St.) and unstabilized composites (Unst.).

Moreover, composites with aligned reinforcement suffer a bigger drop of its properties after stabilization than those where the reinforcement was not aligned. Probably the hydration process suffered by the composite not only plasticizes the matrix polymer but also relieves residual stresses left during the stretching process (alignment process), reducing the effect of the reinforcement alignment. This hypothesis must be verified.

These results are important because although the mechanical properties of the composite are increased through the CNTs alignment, once the thermal stabilization through ethanol is done in this composite, the alignment effects are cancelled out and mechanical properties are reduced.

\section{CONCLUSIONS}

In this study the effect of CNTs addition and stabilization into the mechanical properties of PVA was established. The results allow concluding that in general the addition of CNTs below $0.5 \mathrm{wt} \%$. increases the strength, stiffness and hardness properties of the polymer, making it a potential material for structural applications. Soaking the composite in ethanol successfully increases the thermal degradation temperature of the composite in about $100^{\circ} \mathrm{C}$, suggesting that, in particular for structural applications is recommended a stabilization to increase the resistance to degradation by humidity and temperature. The results also show that the process of mechanical stretching is essential for increasing the properties evaluated while it is shown that the effect on the mechanical properties due to stretching is decreased when the material is subjected to the stabilization with ethanol, which is probably due to the plasticizing effect of water and loss of the CNTs alignment. Additionally, it was found that the polymeric material is stiffened with time (when residual water is loss), increasing the hardness and modulus properties considerably.

\section{ACKNOWLEDGMENTS}

Authors would like to thank to GTS and DIME of the Universidad Nacional de Colombia at Medellín for its support through projects: National Call Support for Strengthening of Research Groups or Artistic Creation that Support Postgraduate Programs of the Universidad Nacional de Colombia and the strategic alliances project: Composite materials reinforced with carbon nanotubes with industrial applications. 


\section{BIBLIOGRAPHY}

[1] PONCHARAL, P., WANG, Z., UGARTE, D., et al. "Electrostatic deflections and electromechanical resonances of carbon nanotubes", Science,v. 283, n. 5407, pp.1513-1516,1999.

[2] SALVETAT, J.-P., BRIGGS, G.A.D., BONARD, J.-M., et al. "Elastic and shear moduli of single-walled carbon nanotube ropes", Physical review letters,v. 82, n. 5, pp.944,1999.

[3] TREACY, M., EBBESEN, T., GIBSON, J. "Exceptionally high Young's modulus observed for individual carbon nanotubes", Nature, 1996.

[4] WONG, E.W., SHEEHAN, P.E., LIEBER, C.M. "Nanobeam mechanics: elasticity, strength, and toughness of nanorods and nanotubes", Science,v. 277, n. 5334, pp.1971-5,1997.

[5] YU, M.-F., LOURIE, O., DYER, M.J., et al. "Strength and breaking mechanism of multiwalled carbon nanotubes under tensile load", Science,v. 287, n. 5453, pp.637-40, 2000.

[6] IIJIMA, S. "Helical microtubules of graphitic carbon", Nature, v. 354, n. 6348, pp.56-58,1991.

[7] GOJNY, F., WICHMANN, M., KÖPKE, U., et al. "Carbon nanotube-reinforced epoxy-composites: enhanced stiffness and fracture toughness at low nanotube content", Composites Science and Technology,v. 64, n. 15, pp.2363-71, 2004.

[8] SPITALSKY, Z., TASIS, D., PAPAGELIS, K., et al. "Carbon nanotube-polymer composites: chemistry, processing, mechanical and electrical properties", Progress in polymer science, v. 35, n. 3, pp.357-401, 2010.

[9] ABDALlA, M., DEAN, D., THEODORE, M., et al. "Magnetically processed carbon nanotube/epoxy nanocomposites: Morphology, thermal, and mechanical properties", Polymer,v. 51, n. 7, pp.1614-20, 2010.

[10] MOISALA, A., LI, Q., KINLOCH, I., et al. "Thermal and electrical conductivity of single-and multiwalled carbon nanotube-epoxy composites", Composites Science and Technology, v. 66, n. 10, pp.1285-8, 2006.

[11] XU, M., FUTABA, D.N., YUMURA, M., et al. "Alignment control of carbon nanotube forest from random to nearly perfectly aligned by utilizing the crowding effect", Acs Nano,v. 6, n. 7, pp.5837-44, 2012.

[12] ZHOU, Y., GHAFFARI, M., LIN, M., et al. "High volumetric electrochemical performance of ultrahigh density aligned carbon nanotube supercapacitors with controlled nanomorphology", Electrochimica Acta,v. 111, n. pp.608-13, 2013.

[13] BRADFORD, P.D., WANG, X., ZHAO, H., et al. "A novel approach to fabricate high volume fraction nanocomposites with long aligned carbon nanotubes", Composites Science and Technology,v. 70, n. 13, pp.1980-5, 2010.

[14] MARCONNET, A.M., YAMAMOTO, N., PANZER, M.A., et al. "Thermal conduction in aligned carbon nanotube-polymer nanocomposites with high packing density", ACS nano,v. 5, n. 6, pp.4818-25, 2011.

[15] WARDLE, B.L., SAITO, D.S., GARCÍA, E.J., et al. "Fabrication and Characterization of Ultrahigh Volume - Fraction Aligned Carbon Nanotube-Polymer Composites", Advanced Materials,v. 20, n. 14, pp.2707-14, 2008.

[16] ROY, N., SENGUPTA, R., BHOWMICK, A.K. "Modifications of carbon for polymer composites and nanocomposites", Progress in Polymer Science, v. 37, n. 6, pp.781-819,2012.

[17] MONTI, M., NATALI, M., TORRE, L., et al. "The alignment of single walled carbon nanotubes in an epoxy resin by applying a DC electric field", Carbon,v. 50, n. 7, pp.2453-64,2012.

[18] KHAN, S.U., POTHNIS, J.R., KIM, J.-K. "Effects of carbon nanotube alignment on electrical and mechanical properties of epoxy nanocomposites", Composites Part A: Applied Science and Manufacturing,v. 49, n. pp.26-34,2013.

[19] GOH, P.S., ISMAIL, A.F., NG, B.C. "Directional alignment of carbon nanotubes in polymer matrices: contemporary approaches and future advances", Composites Part A: Applied Science and Manufacturing,v. 56, n. pp.103-26, 2014.

[20] FILPO, G., SIPROVA, S., CHIDICHIMO, G., et al. "Alignment of single-walled carbon nanotubes in polymer dispersed liquid crystals", Liquid Crystals,v. 39, n. 3, pp.359-64,2012.

[21] SUN, X., CHEN, T., YANG, Z., et al. "The alignment of carbon nanotubes: an effective route to extend their excellent properties to macroscopic scale", Accounts of chemical research,v. 46, n. 2, pp.539-49,2012.

[22] GUO, W., LIU, C., SUN, X., et al. "Aligned carbon nanotube/polymer composite fibers with improved 
mechanical strength and electrical conductivity", Journal of Materials Chemistry,v. 22, n. 3, pp.903-8, 2012. [23] ROMYEN, N., THONGYAI, S., PRASERTHDAM, P. "Alignment of carbon nanotubes in polyimide under electric and magnetic fields", Journal of Applied Polymer Science,v. 123, n. 6, pp.3470-3475, 2012.

[24] ERB, R.M., LIBANORI, R., ROTHFUCHS, N., et al. "Composites reinforced in three dimensions by using low magnetic fields", Science,v. 335, n. 6065, pp.199-204,2012.

[25] ALI, U., ZHOU, Y., WANG, X., et al. "Direct electrospinning of highly twisted, continuous nanofiber yarns", Journal of the Textile Institute,v. 103, n. 1, pp.80-88, 2012.

[26] ISAZA, C., MEDINA, S., GALLEGO, G.S., et al. "Estudio de las propiedades mecánicas del alcohol polivinílico reforzado con nanotubos de carbono orientados mecanicamente", Revista Colombiana de Materiales, n. 5, pp.93-9, 2014.

[27] CHENG, Q., LIANG, R., WANG, B., et al. Composite Materials and Method for Making HighPerformance Carbon Nanotube Reinforced Polymer Composites, Google Patents, 2013.

[28] COLEMAN, J.N., CADEK, M., BLAKE, R., et al. "High performance nanotube - reinforced plastics: Understanding the mechanism of strength increase", Advanced Functional Materials, v. 14, n. 8, pp.791-798, 2004.

[29] HONG, Y., SHANG, T., LI, Y., et al. "Synthesis using electrospinning and stabilization of single layer macroporous films and fibrous networks of poly (vinyl alcohol)", Journal of membrane science,v. 276, n. 1, pp.1-7, 2006.

[30] PROBST, O., MOORE, E.M., RESASCO, D.E., et al. "Nucleation of polyvinyl alcohol crystallization by single-walled carbon nanotubes", Polymer,v. 45, n. 13, pp.4437-4443, 2004.

[31] SCOPUS, http://www.scopus.com/, Analyze search results. Accessed in March 2014.

[32] GALlegO, G.S., BARRAUlT, J., BATIOT-DUPEYRAT, C., et al. "Production of hydrogen and MWCNTs by methane decomposition over catalysts originated from LaNiO 3 perovskite", Catalysis Today,v. 149, n. 3, pp.365-71, 2010.

[33] MEZA, J.M., FARIAS, M.C.M., SOUZA, R.M.D., et al. "Using the ratio: maximum load over unload stiffness squared, $\mathrm{Pm} / \mathrm{Su}^{2}$, on the evaluation of machine stiffness and area function of blunt indenters on depth-sensing indentation equipment", Materials Research,v. 10, n. 4, pp.437-47, 2007.

[34] PERKINELMER, I. Characterization of Polymers Using TGA, United States, PerkinElmer, 2011.

[35] SHAFFER, M.S.P., FAN, X., WINDLE, A. "Dispersion and packing of carbon nanotubes", Carbon,,v. 36, n. pp.1603-1612,1998.

[36] KELEN, T. "Polymer Degradation", Van Nostrand Reinhold, New York, 1983. 